\title{
ERRATUM
}

\section{Giant Intrahepatic Biloma Following Blunt Hepatic Injury - ERRATUM}

doi:10.1017/cem.2015.106

In the original publication of "Giant Intrahepatic Biloma Following Blunt Hepatic Injury," the firstnamed author was improperly listed as Chien-Ze Peng. The author's correct name is Chian-Ze Peng. The publisher regrets this error.

\section{REFERENCE}

1. Chian-Ze P, Chien-Ying W. Giant Intrahepatic Biloma Following Blunt Hepatic Injury. CFEM 2015; epub, doi: $10.1017 / \mathrm{cem} .2015 .106$. 